05;06;07

\title{
Генерация терагерцевого излучения в магнитных переходах на основе нанопроволок
}

\author{
() Ю.В. Гуляев ${ }^{1}$, С.Г. Чигарев ${ }^{1}$, А.И. Панас ${ }^{2, \llbracket, ~ Е . А . ~ В и л к о в ~}{ }^{1}$, Н.А. Максимов ${ }^{1}$, \\ Д.Л. Загорский ${ }^{3}$, А.С. Шаталов ${ }^{3}$ \\ ${ }^{1}$ Институт радиотехники и электроники им. В.А. Котельникова РАН, Фрязино, Россия \\ ${ }^{2}$ АО „НПП „Исток“ им. Шокина“, Фрязино, Россия \\ ${ }^{3}$ Институт кристаллографии им. А.В. Шубникова ФНИЦ „Кристаллография и фоотоника“ РАН, Москва, Россия \\ IE-mail: aipanas@istokmw.ru
}

Поступило в Редакцию 13 декабря 2018г.

В окончательной редакции 17 декабря 2018г.

Принято к публикации 17 декабря 2018г.

\begin{abstract}
Исследуется система, состоящая из спин-инжекционных излучателей, использующих магнитные переходы на основе массива параллельных наноразмерных проволок. Описываются технология изготовления и возможные варианты структуры нанопроволок. Обсуждаются условия формирования на их основе спининжекционных излучателей терагерцевого диапазона нового типа. Описывается структура экспериментального макета и анализируются результаты экспериментов. Продемонстрирована возможность генерации сигнала в диапазоне частот $16-18 \mathrm{THz}$ при пропускании тока высокой плотности через указанный массив.
\end{abstract}

DOI: 10.21883/PJTF.2019.06.47495.17641

В последнее время внимание специалистов все больше привлекает терагерцевый (THz) диапазон частот. Интерес к нему подогревается свойствами соответствующих ему сигналов, которые весьма привлекательны для потенциального практического применения. Например, тот факт, что THz-излучение не является ионизирующим и в отличие от рентгеновского излучения не наносит вреда организму, делает его весьма перспективным для сканирующих систем безопасности и медицины. Потенциально широкие рабочие полосы привлекают внимание специалистов с связи с возможностью создания суперскоростных систем связи, а длины волн, соизмеримые с типовыми размерами микромира, интересны для решения различных материаловедческих проблем [1].

С другой стороны, THz-диапазон расположен между инфракрасным и сверхвысокочастотным диапазонами и ввиду своей слабой освоенности иногда называется „терагерцевой дырой“ (или „провалом“). Такая ситуация связана с небольшим выбором существующих источников и приемников THz-излучения, как правило довольно габаритных и/или низкоэффективных. И хотя специалисты считают, что „провал“ сомкнулся к концу 90-х годов, принципиально ситуация в наши дни мало изменилась. Кроме того, она осложняется и проблемами с измерительной аппаратурой в указанном диапазоне.

Отмеченные обстоятельства делают актуальными исследования по поиску новых научно-технических и технологических решений, связанных с разработкой малогабаритных и по возможности эффективных устройств излучения и приема в $\mathrm{THz}$-диапазоне.

В последние 10-15 лет преимущественно в России развивается новое направление исследований, связанное с эффектом излучения THz-сигналов (в диапазоне частот $3-40 \mathrm{THz})$ в магнитных переходах, сформированных из контактирующих слоев ферромагнетиков и антиферромагнетиков, при протекании через них токов большой плотности $\left(10^{5}-10^{7} \mathrm{~A} / \mathrm{cm}^{2}\right)$. Начало исследованиям положили теоретические работы [2-4], предсказавшие возможность спин-инжекционного излучения в указанных структурах и объяснившие эффект. Далее последовали эксперименты, по мнению авторов подтвердившие предсказанное теоретиками явление [5,6]. Публикации результатов экспериментов стимулировали новый виток интереса к рассматриваемой проблеме, демонстрируемый ведущими научно-техническими изданиями и специалистами.

Одно из направлений исследований последних лет в этой области связано с попытками авторов увеличить интегральную мощность ТНz-излучения. Ее оценка в проведенных экспериментах варьируется в пределах десятка-сотен микроватт, что недостаточно для потенциальных приложений. Интересные результаты были получены при помещении источника THz-излучения (излучателя) в резонатор с положительной обратной связью подобно лазерам. Показано $[7,8]$, что такой подход позволяет резко увеличить интенсивность генерации. Другой подход связан с увеличением числа излучателей, что также приводит к увеличению мощности излучения.

Развитием второго подхода является настоящая работа, цель которой состоит в использовании в качестве основных элементов излучателей наноразмерных проволок. Основной ее идеей является использование структуры с массивом параллельных наноразмерных проволок для формирования в каждой из них магнитных переходов. О таких структурах известно с 90-х годов прошлого столетия. Один из способов их получения матричный синтез, согласно которому заранее изготовленные микропоры в одном из материалов (матрицы) 


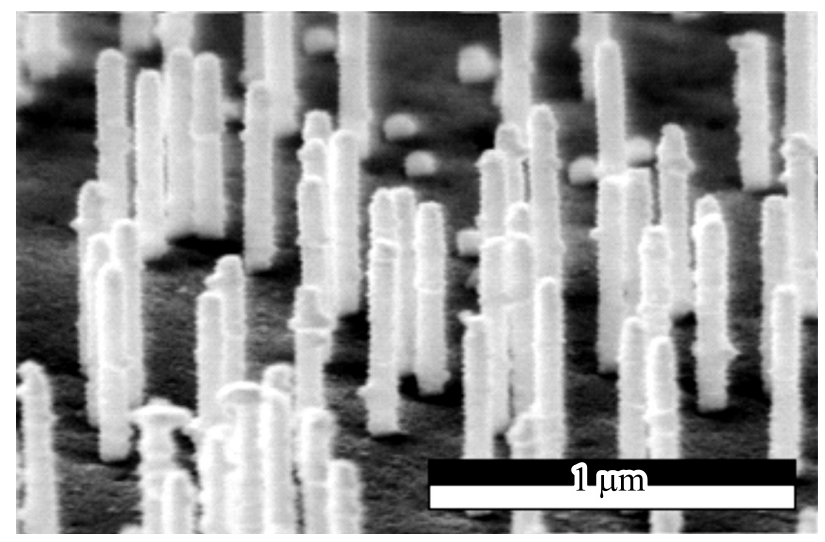

Рис. 1. Электронно-микроскопическое изображение структуры с массивом нанопроволок после удаления полимерной ростовой матрицы

заполняются другим материалом [9]. Одним из методов заполнения пор является метод гальванического осаждения, используемый в настоящей работе. Такая технология дает, в частности, возможность получения нанопроволок, состоящих из нескольких (чередующихся) слоев различных металлов (сплавов) [10-12]. Получаемые при этом структуры могут обладать гигантским магнетосопротивлением и применяются в качестве магнитных сенсоров и датчиков.

В качестве ростовой матрицы использовалась полимерная трековая мембрана, представляющая собой тонкую пленку (полиэтилентерефталат) толщиной $10 \mu \mathrm{m}$ со множеством идентичных сквозных цилиндрических пор (поверхностная плотность $10^{8}$ пор на $\mathrm{cm}^{2}$ ) диаметром порядка $100 \mathrm{~nm}$. Технология получения пор в такой мембране связана с облучением ее тяжелыми ускоренными ионами и последующим вытравливанием образовавшихся латентных треков.

Наноразмеры получаемых проволок и возможность синтезировать в каждой из них структуры с различными магнитными свойствами (ферромагнетик-ферромагнетик, ферромагнетик-антиферромагнетик, ферромагнетик-парамагнетик и т.п.) стимулировали идею о создании на их основе спин-инжекционных излучателей.

В том случае, когда необходимо создать лишь один переход, предпочтительно применение „двухваннового“ метода, при котором используются два электролита и каждый слой выращивается в „своем“ электролите. Этот подход существенно улучшает качество формируемых слоев по сравнению с традиционно используемым „однованновым“ методом. Именно с помощью „двухваннового“ метода были получены структуры с комбинациями в каждой отдельно взятой поре железа и никеля, которые далее и исследовались в работе. На рис. 1 представлен пример электронно-микроскопического изображения указанной структуры после отделения массива нанопроволок от ростовой матрицы.
Для создания условий генерации в полученных магнитных переходах необходимо обеспечить протекание тока через массив нанопроволок. С этой целью на обе поверхности трековых мембран наносятся слои металла, к которым подсоединяется источник электропитания. При этом один из контактных слоев (слой меди толщиной несколько микрометров) наносится на поверхности мембраны перед осаждением металлов в поры, а другой из указанных слоев должен быть еще и полупрозрачным для THz-излучения. Эту функцию выполнял слой золота толщиной порядка $20 \mathrm{~nm}$, нанесенный плазменным распылением. К обоим металлическим слоям подсоединялись массивные токоподводящие электроды.

Экспериментальная установка позволяла фиксировать спектры излучаемого сигнала при изменении тока источника питания. Сначала оценивался диапазон рабочих токов и определялся диапазон излучения с помощью THz-фильтров фирмы TYDEX. Далее исследовались спектры излучаемого сигнала в зависимости от тока источника питания с помощью инфракрасного фурье-спектрометра Vertex 80V фирмы Bruker.

На рис. 2 приведены спектральные характеристики фиксируемого в экспериментах излучения в зависимости от величины протекающего через структуру тока. Для удобства их сравнения они представлены в нормированном масштабе. Как и в предыдущих работах авторов, здесь также наблюдается ярко выраженный пороговый эффект по протекающему через экспериментальный образец интегральному току. При превышении им значения в $68 \mathrm{~mA}$ в спектре начинают резко проявляться спектральные (излучательные) компоненты в диапазоне частот 16-18 THz. При дальнейшем увеличении тока мощность излучения увеличивается, оставаясь в пределах указанного частотного диапазона. Такая частотная избирательность резко отличается от поведения тепловых спектров (кривые 1,2) в данном диапазоне и свидетельствует о нетепловом характере излучения.

Приведенные в работе результаты экспериментов подтвердили возможность использования массива нанопроволок в качестве ансамбля основных элементов спининжекционных излучателей. Получена устойчивая гене-

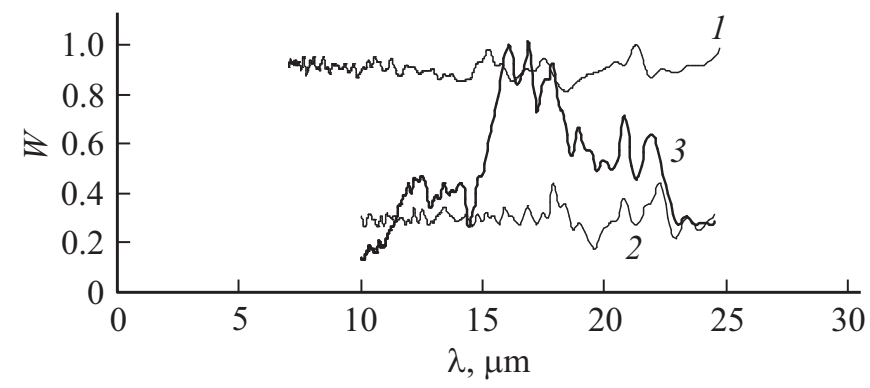

Рис. 2. Спектр излучаемого сигнала $(W-$ мощность сигнала в относительных единицах, $\lambda-$ длина волны излучаемого сигнала) в зависимости от интегральной величины тока, протекающего через экспериментальный макет. 1 - спектр Глобара (тепловой инфракрасный источник), $2-30 \mathrm{~mA}, 3-82 \mathrm{~mA}$. 
рация сигнала в диапазоне $16-18 \mathrm{THz}$. На данный момент это первые экспериментальные результаты. Поэтому для того чтобы оценить перспективы использования нанопроволок по крайней мере с точки зрения увеличения интегральной мощности излучения рассмотренных структур, необходимо продолжение экспериментальных работ в этом направлении.

Авторы благодарят В.А. Артемова (ФНИЦ „Кристаллография и фотоника“ РАН) за помощь в получении электронных изображений массива нанопроволок, а также Федеральное агентство научных организаций (ФАНО РАН) за поддержку в проведении экспериментальной работы (соглашение № 007-ГЗ/Ч3363/26). Работа выполнена при частичной финансовой поддержке Российского фонда фундаментальных исследований (18-29-27020 мк).

\section{Список литературы}

[1] Dhillon S.S., Vitiell M.S., Linfield E.H., Davies A.G., Hoffmann M.C., Booske J., Paoloni C., Gensch M., Weightman P., Williams G.P., Castro-Camus E., Cumming D.R.S., Simoens F., Escorcia-Carranza I., Grant J., Lucyszyn S., Kuwata-Gonokami M., Konishi K., Koch M., Schmuttenmaer C.A., Cocker T.L., Huber R., Markelz A.G., Taylor Z.D., Wallace V.P., Zeitler J.A., Sibik J., Korter T.M., Ellison B., Rea S., Goldsmith P., Cooper K.B., Appleby R., Pardo D., Huggard P.G., Krozer V., Shams H., Fice M., Renaud C., Seeds A., Stöhr A., Naftaly M., Ridler N., Clarke R., Cunningham J.E., Johnston M.B. // J. Phys. D: Appl. Phys. 2017. V. 50. P. 1-49.

[2] Гуляев Ю.В., Зильберман П.Е., Эпштейн Э.М., Эллиот Р.Джс. // Радиотехника и электроника. 2003. Т. 48. № 3. C. $1030-1044$.

[3] Kadigrobov A., Shekhter R.I., Jonson M. // ФHT. 2005. T. 31. B. 3-4. C. 463-470.

[4] Гуляев Ю.В., Зильберман П.Е., Чигарёв С.Г., Эпитейн Э.М. // Письма в ЖТФ. 2011. В. 4. С. 16-22.

[5] Гуляев Ю.В., Зильберман П.Е., Маликов И.В., Михайлов Г.М., Панас А.И., Чигарёв С.Г., Эпштейн Э.М. // Письма в ЖЭТФ. 2011. Т. 93. В. 5. С. 289-292.

[6] Гуляев Ю.В., Зильберман П.Е., Маликов И.В., Михайлов Г.М., Панас А.И., Чигарёв С.Г., Эпштейн Э.М. // ДАН. 2011. T. 438. № 1. С. 41-43.

[7] Гуляев Ю.В., Вилков Е.А., Зильберман П.Е., Михайлов Г.М., Черных Ф.В., Чигарев С.Г. // Письма в ЖЭТФ. 2014. T. 99. B. 9. C. 591-594.

[8] Гуляев Ю.В., Вилков Е.А., Зильберман П.Е., Михайлов Г.М., Черных Ф.В., Чигарев С.Г. // Радиотехника и электроника. 2015. Т. 60. № 9. С. 963-966.

[9] Martin C.R. // Science. 1994. V. 266. P. 1961-1966.

[10] Magnetic nano- and microwires: design, synthesis, properties and applications / Ed. M. Vázquez. Amsterdam: Elsevier, 2005. $847 \mathrm{p}$.

[11] Ohgai T. // Electrodeposited nanowires and their applications / Ed. N. Lupu. InTech, 2010. P. 61-85.

[12] Давыдов А.Д., Волгин В.М. // Электрохимия. 2016. Т. 52. № 9. С. 905-933. 